\section{PLAYING THE BUILDING}

Artist and musician David Byrne, lead singer of the rock group Talking Heads, has transformed New York's Battery Maritime Building into a giant musical instrument. By tapping on the keys of an antique organ, visitors to the historic disused ferry terminal - open Fridays to Sundays until 10 August - can make its pipes, beams and spaces sing out harmoniously as installed devices strike, vibrate and blow through the building's structure. www.davidbyrne.com

\section{EYEING THE UNIVERSE}

An inspirational array of astronomy photographs graces the Albert Dock in Liverpool, UK, this month. The exhibit will tour the world as part of the International Year of Astronomy 2009 celebrations after marking Liverpool's status as this year's European Capital of Culture. Pictures of planets, stars, nebulae and galaxies from observatories on Earth and in orbit, including the Hubble Space Telescope, were chosen by astronomers to convey the beauty of the Universe. http://tinyurl.com/6meufd

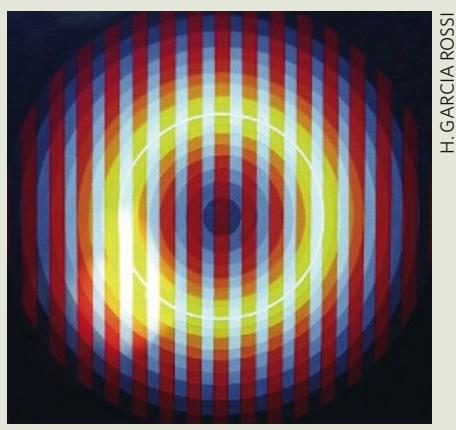

\section{PAINTING WITH PERCEPTION}

French optical artists from the Group of Visual Arts Research, who explored visual effects in painting in the 1960s, are the subject of an exhibition at the State Hermitage Museum in St Petersburg, Russia, running until 14 September. The artists painted optical effects and illusions on canvas, such as Horacio Garcia Rossi's Electric Colour Light (above), using knowledge of how the human eye works. By focusing on physiology and physics, their aim was to produce art that anyone can experience, regardless of cultural origin, status or education. www.hermitagemuseum.org
In an ideal world, profit would not influence research. As a banner carried by an anti-globalization demonstrator at an international trade conference in Genoa proclaimed: "Capitalism should be replaced by something nicer." However, the socialist alternative, as exemplified by the former Soviet Union, did not prove to be 'nicer'. By stifling opposition to his ideas, Stalin's director of biology, Trofim Lysenko, did not promote good science, nor did he benefit the Soviet public.

Profit-pursuing corporations are not the only sinners to disrespect the integrity of science. Polls show that whereas the public distrusts scientists funded by industry, it respects those who work for environmental non-governmental organizations such as Greenpeace and Friends of the Earth. They are assumed to be objective and public spirited. Yet those bodies also have their own agendas, namely to promote their causes by increasing membership; they know that the most effective appeal is through scare stories. They too ignore and distort evidence, but in their case there is no self-regulatory mechanism. The more sensational the scare - for example, "Frankenfoods!" - the greater the publicity.

Michaels describes how defenders of the tobacco industry exploited the uncertainties of science by promoting doubt: they demanded that tobacco should be positively proved to cause harm. Green lobbyists make the equally unjustifiable demand that genetically modified crops should be positively proved to be safe. Reports on transgenic crops by the World Health Organization, by every national academy of science and their worldwide cultivation for more than ten years provide no evidence of harm to human health. Yet environmental organizations ignore this. They constantly recycle discredited findings by Árpád Pusztai in 1999 and Irina Ermakova in 2007 that transgenic crops cause harm to rats, and continue to make long-disproved claims that transgenic maize is destroying monarch butterflies.

The motives of these green activists are ideological not financial, based on fears that science has gone too far and we must go 'back to nature', and that transgenic crops benefit only big corporations. More than ten million small-scale farmers have benefited from transgenic crops, mainly farmers of genetically modified cotton, who saw improvements in health and income from the reduced need to spray pesticides. Confident of the virtue of their cause, Greenpeace, Friends of the Earth and the Soil Association feel no need for peer-reviewed papers and show less regard for evidence than the large corporations they denounce.

Doubt Is Their Product underlines the

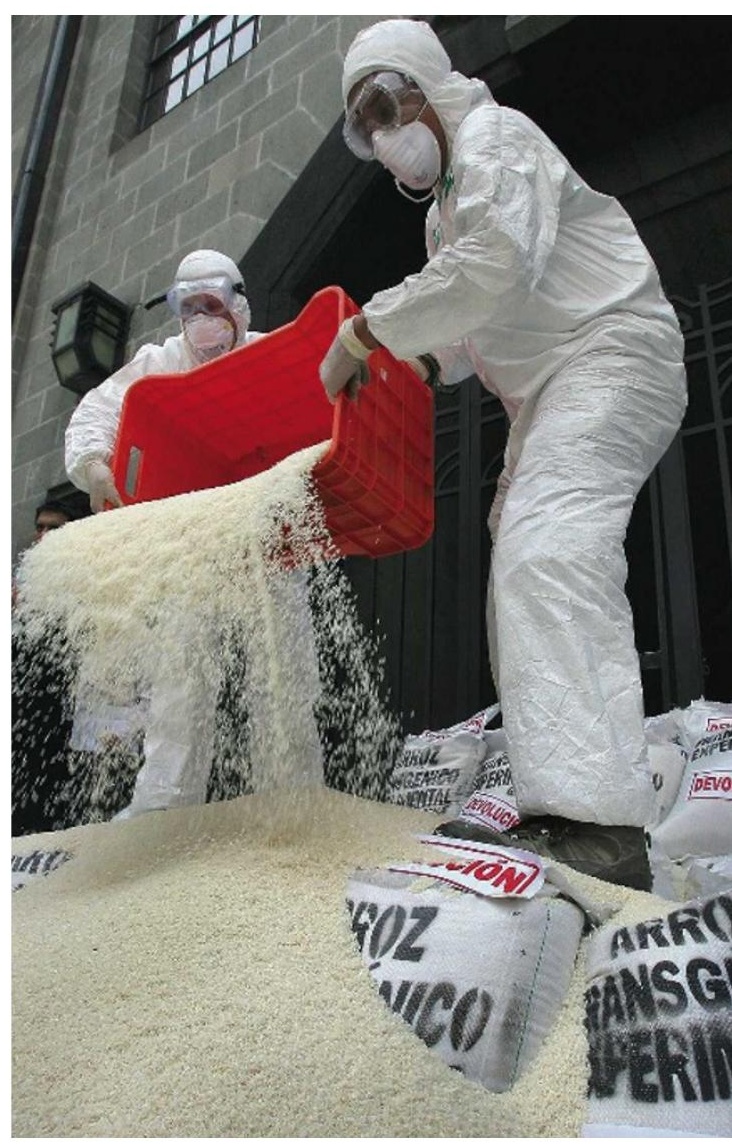

Despite scientific evidence, environmentalists oppose transgenic crops such as modified rice.

need for independent regulation. Michaels records how George W. Bush's administration applied political pressure to undermine the independence of regulators in the United States, and demonstrates the perils of trusting corporations themselves to protect the public interest. In Europe, the threat to science comes from another quarter: the excessive influence of over-zealous green campaigners, who have virtually driven agricultural biotechnology into exile.

The moral is that we must all recognize our tendency to judge evidence with a bias towards our own interests and beliefs. This makes it especially incumbent on those with corporate connections to ensure that respect for evidence predominates in industry-financed research. Equally, those of us who care passionately about the environment must be on our guard to ensure that green causes do not ignore or distort the scientific evidence on which their success depends.

Dick Taverne is chairman of Sense About Science, a member of the UK House of Lords Committee on Science and Technology and author of The March of Unreason - Science, Democracy and the New Fundamentalism. 